\title{
Electron postgrowth irradiation of platinum-containing nanostructures grown by electron-beam-induced deposition from $\mathrm{Pt}\left(\mathrm{PF}_{3}\right)_{4}$
}

\author{
A. Botman a) and C. W. Hagen \\ Faculty of Applied Sciences, Delft University of Technology, Lorentzweg 1, 2628 CJ Delft, The Netherlands \\ J. Li, B. L. Thiel, and K. A. Dunn \\ College of Nanoscale Science and Engineering, University at Albany-SUNY, 251 Fuller Road, Albany, \\ New York 12203 \\ J. J. L. Mulders \\ FEI Electron Optics, Achtseweg Noord 5, 5600 KA Eindhoven, The Netherlands \\ S. Randolph and M. Toth \\ FEI Company, 5350 NE Dawson Creek Drive, Hillsboro, Oregon 97124
}

(Received 7 July 2009; accepted 28 September 2009; published 2 December 2009)

\begin{abstract}
The material grown in a scanning electron microscope by electron beam-induced deposition (EBID) using $\mathrm{Pt}\left(\mathrm{PF}_{3}\right)_{4}$ precursor is shown to be electron beam sensitive. The effects of deposition time and postgrowth electron irradiation on the microstructure and resistivity of the deposits were assessed by transmission electron microscopy, selected area diffraction, and four-point probe resistivity measurements. The microstructure, notably the platinum nanocrystallite grain size, is shown to evolve with electron fluence in a controllable manner. The resistivity was observed to decrease as a result of postgrowth electron irradiation, with the lowest observed value of $215 \pm 15 \mu \Omega \mathrm{cm}$. The authors demonstrate that electron beam-induced changes in microstructure can be caused using electron fluences similar to those used during the course of EBID and suggest that the observed effects can be used to tailor the microstructure and functionality of deposits grown by EBID in situ without breaking vacuum. (C) 2009 American Vacuum Society. [DOI: 10.1116/1.3253551]
\end{abstract}

\section{INTRODUCTION}

Electron-beam-induced deposition ${ }^{1,2}$ (EBID) allows the rapid fabrication of three dimensional nanodevices and the wiring of nanostructures by scanning and transmission electron microscopy (SEM/TEM). A gaseous precursor is introduced into the microscope specimen chamber where it adsorbs onto a solid substrate. Through its interaction with the substrate, the electron beam locally decomposes (dissociates) the adsorbates, giving rise to deposition. A wide range of materials and deposit geometries can be fabricated through appropriate selection of precursor type and electron exposure strategy. Since deposition is achieved by a one step electron exposure procedure, EBID is known as a direct-write process. Typical applications of EBID include contacting of carbon nanotubes ${ }^{3}$ and growth of tips for field emission ${ }^{4}$ and magnetic force microscopy. ${ }^{5}$ The deposited material often includes substantial amounts of undesired elements such as carbon and oxygen originating from species present in the precursor and contaminants present in the EBID process chamber. To mitigate carbon coinclusion in deposits, a carbon-free precursor, tetrakis trifluorophosphine platinum $\left(\mathrm{Pt}\left(\mathrm{PF}_{3}\right)_{4}\right)$ can be used. ${ }^{6,7}$ The material grown from $\mathrm{Pt}\left(\mathrm{PF}_{3}\right)_{4}$ is a beam-sensitive ${ }^{7}$ nanocomposite composed of platinum nanocrystallites embedded in an amorphous matrix. ${ }^{8,9}$ Here, we present results that demonstrate the effects of the electron

\footnotetext{
a) Author to whom correspondence should be addressed; present address: FEI company, 5350 NE Dawson Creek Drive, Hillsboro, Oregon 97124; electronic mail: aurelien.botman@fei.com
}

fluence (time-integrated flux) used for EBID and of postgrowth electron irradiation [performed after deposition, in the absence of $\left.\mathrm{Pt}\left(\mathrm{PF}_{3}\right)_{4}\right]$ on deposit properties. Specifically, we show the dependence of microstructure and resistivity on growth time and postgrowth irradiation time.

\section{METHOD}

Results from two deposition methods are reported in this article: EBID performed by environmental scanning electron microscopy (ESEM) (Ref. 10) and EBID performed by highvacuum (HV) SEM. $\mathrm{Pt}\left(\mathrm{PF}_{3}\right)_{4}$ was the deposition precursor used in all experiments. In the ESEM method, the entire chamber was filled with $\mathrm{Pt}\left(\mathrm{PF}_{3}\right)_{4}$ to a pressure of approximately 0.2 mbar. The HV approach refers to the conventional method of EBID, whereby the base pressure is approximately equal to $10^{-6} \mathrm{mbar}$, and the precursor is injected into the vicinity of the beam impact point at the sample surface via a gas injection system ${ }^{11}$ (GIS), such that the chamber background pressure increases to approximately 5 $\times 10^{-5}$ mbar (although the local partial pressure at the end of the GIS needle is much higher ${ }^{11}$ ). ESEM EBID was performed using a defocused stationary beam (yielding a top-hat electron flux profile ${ }^{10}$ ), whereas HV deposition was performed with a focused, scanned beam. Qualitatively, the results discussed in the present article were independent of the EBID methodology (HV or ESEM) and irradiation strategy (defocused stationary or focused scanned electron beam). 


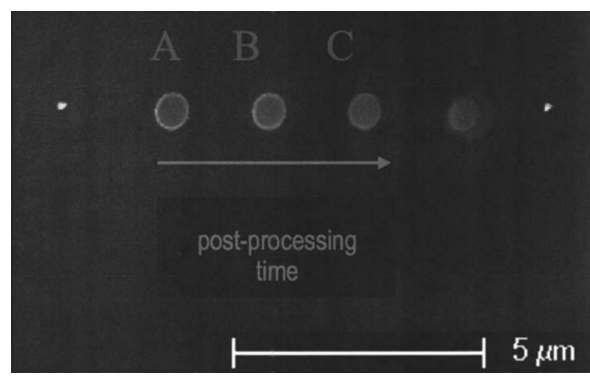

FIG. 1. Four deposits grown in ESEM mode (0.21 mbar) on a bulk Si substrate with a defocused stationary beam $(20 \mathrm{keV}, 790 \mathrm{pA}, 4 \mathrm{~min})$, between two pillars grown using a focused electron beam (used as markers for TEM sample preparation). Deposit A was left as is, while deposits B and C were irradiated in a high-vacuum environment with a $20 \mathrm{keV}, 7.2 \mathrm{nA}$ electron beam for 2 and $10 \mathrm{~min}$, respectively. This secondary electron image was taken after postgrowth electron irradiation.

Samples made for resistivity measurements were deposited on prepatterned Au electrodes on an insulating $\mathrm{SiO}_{x}$ substrate. The measurements were done using a four-point probe station.

\section{RESULTS}

To study the effects of postgrowth electron irradiation, four deposits were fabricated in ESEM mode (0.21 mbar) onto a bulk $\mathrm{Si}$ substrate using a defocused stationary beam (20 keV, $790 \mathrm{pA}, 4 \mathrm{~min}$ ). Two additional pillar deposits were grown using a focused electron beam to serve as markers for TEM sample preparation. Figure 1 shows the deposits, labeled A, B, C, and D. The electron flux used for EBID was $1.5 \times 10^{4}$ electrons $\mathrm{nm}^{-2} \mathrm{~s}^{-1}$. After deposition the samples were stored in air. A few days later they were placed back into the same SEM, and the electron beam was used to irradiate the deposits in a high-vacuum environment (in the absence of a precursor gas) to various electron fluences. The irradiation was performed using a stationary, $20 \mathrm{keV}$ electron beam, a current of $7.2 \mathrm{nA}$, and a fluence of 5.8 $\times 10^{4}$ electrons $\mathrm{nm}^{-2} \mathrm{~s}^{-1}$. Deposits $\mathrm{A}, \mathrm{B}$, and $\mathrm{C}$ were irradiated for 0,2 , and $10 \mathrm{~min}$, respectively. (Deposit D was lost during TEM sample preparation.) The image in Fig. 1 was taken after the electron irradiation treatment.

Figure 2 shows cross-sectional scanning TEM high angle annular dark field (STEM-HAADF) images of deposits A, B,

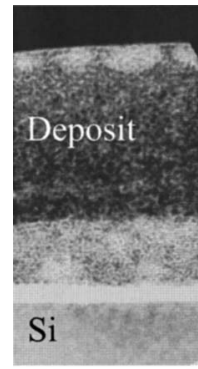

A

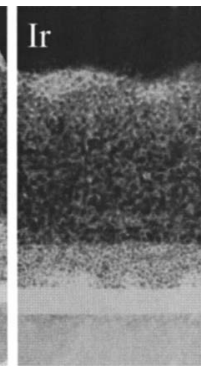

B

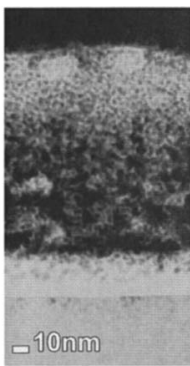

C
FIG. 2. Cross-sectional STEM-HAADF images of deposits A, B, and C shown in Fig. 1 (the deposits are coated with an iridium protective layer).

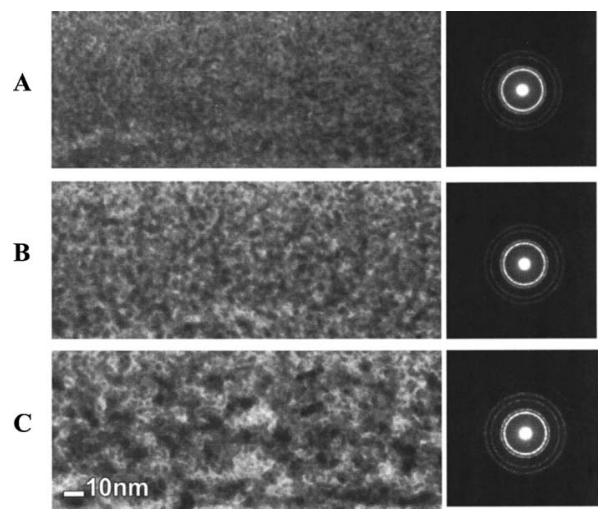

FIG. 3. Cross-sectional TEM images and corresponding SAD patterns of deposits $\mathrm{A}, \mathrm{B}$, and $\mathrm{C}$ shown in Fig. 1, taken from the center of each deposit.

and $\mathrm{C}$ (the deposits are coated with an iridium protective layer). The mean particle size and the local material density both appear to increase with postgrowth electron irradiation time. In Fig. 3, cross-sectional TEM images and corresponding selected area diffraction (SAD) patterns taken from the center of each deposit are shown. Both the images and the SAD patterns were taken under the same experimental conditions and indicate an increase in the platinum nanocrystallite grain size with postgrowth electron fluence. ${ }^{10}$

A second set of samples was made to illustrate the effect of electron irradiation on grain size, quantitatively and systematically. These deposits were grown in HV mode on a thin carbon film with a focused beam, a background chamber pressure (during deposition) of $1.3 \times 10^{-5}$ mbar, a beam energy and current of $5 \mathrm{keV}$ and $1.6 \mathrm{nA}$, a scan area of 2 $\times 2 \mu \mathrm{m}^{2}$, a dwell time of $1 \mu \mathrm{s}$, and no pixel overlap. The deposits were grown on a thin carbon film to enable direct TEM analysis without further preparation. Three sets of samples were made; thin (using a deposition time of $75 \mathrm{~s}$, yielding a height of $15 \mathrm{~nm})$, intermediate $(150 \mathrm{~s}, 30 \mathrm{~nm})$, and thick $(250 \mathrm{~s}, 50 \mathrm{~nm})$. The samples were then irradiated in the absence of precursor, several days later, under the following conditions: focused electron beam, $5 \mathrm{keV}, 1.5 \mathrm{nA}$, $1 \mu$ s pixel dwell time, a scan area of $3 \times 3 \mu \mathrm{m}^{2}, 80 \%$ pixel overlap, and a background pressure of $3 \times 10^{-6}$ mbar. The irradiation times were $1,2,5,10$, and $20 \mathrm{~min}$. A set of asgrown deposits that were not processed by an electron beam after growth was retained for reference.

Figure 4 shows a plot of the mean grain size as a function of postgrowth electron irradiation time obtained from the thin and thick deposits (the third sample set is not shown for clarity but follows the same trend). Each data point was obtained by averaging 20 grains from a high-resolution, $200 \mathrm{keV}$ TEM low-dose bright-field image taken from the center of each deposit. The data show that the grain diameter increases with irradiation time, from $1.98 \pm 0.26 \mathrm{~nm}$ (asgrown material) to $3.50 \pm 0.35 \mathrm{~nm}$ (postgrowth irradiation time of $20 \mathrm{~min}$ ). Two TEM images of thin samples are shown in Fig. 5, illustrating the case of an as-grown material and a deposit subjected to a 20 min postgrowth irradiation treatment. 


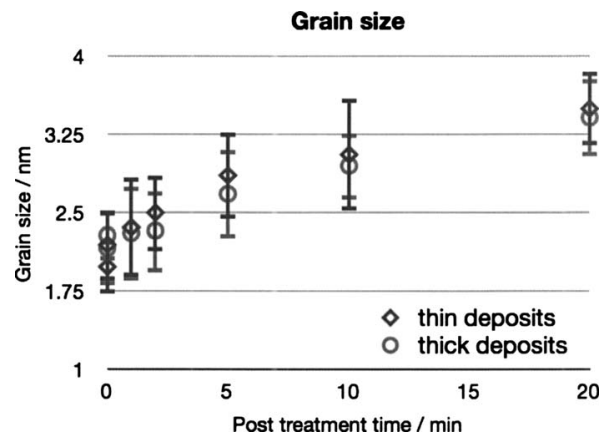

FIG. 4. Dependence of the mean platinum nanocrystallite diameter on postgrowth irradiation time. The grain size increases from $1.98 \pm 0.26$ to $3.50 \pm 0.35 \mathrm{~nm}$.

The EBID growth direction is away from the substratevacuum interface. During deposition the electron beam penetrates pre-existing, already-grown solid, giving rise to an electron beam irradiation treatment during deposition. ${ }^{10}$ Hence, in the case of deposits thinner than the electron penetration range, we expect an increase in crystallinity and grain size with growth time. Figure 6 shows high-resolution TEM images of six deposits grown on a thin carbon membrane in $\mathrm{HV}$ mode (the background chamber pressure during deposition was $1.3 \times 10^{-5} \mathrm{mbar}$ ), using a focused $5 \mathrm{keV}$, $1.8 \mathrm{nA}$ electron beam scanned over an area of 8.5 $\times 0.8 \mu \mathrm{m}^{2}$ with a $1 \mu$ s dwell time (0\% pixel overlap). The deposition time ranged from 10 to $300 \mathrm{~s}$. The images were taken from the center of each deposit and illustrate qualitatively that both crystallinity and grain size increase with deposition time. The images are unsuitable for quantitative analysis because the deposit thickness increased significantly with growth time.

The observed changes in crystallinity, density, and nanocrystallite size are expected to affect resistivity. Table I shows that the resistivity of material grown from $\mathrm{Pt}\left(\mathrm{PF}_{3}\right)_{4}$ decreases with increasing deposition time and Table II shows that it increases with increasing beam diameter. Both datasets show that the resistivity decreases with electron fluence (an increase in beam diameter at a fixed dose corresponds to a decrease in electron fluence).

Finally, a number of identical deposits were grown in ESEM mode, irradiated in the absence of precursor for various lengths of time, and the effect of irradiation time on resistivity was examined directly. The deposits were made using a $20 \mathrm{keV}$ defocused stationary electron beam scanned in one dimension (along a line), for 15 min using a beam current and $\mathrm{Pt}\left(\mathrm{PF}_{3}\right)_{4}$ pressure of $7.2 \mathrm{nA}$ and 0.19 mbar and a flux of $3.4 \times 10^{5}$ electrons $\mathrm{nm}^{-2} \mathrm{~s}^{-1}$. Postgrowth irradiation was performed in a high-vacuum environment for 10 or 30 min using a beam energy, current, and flux of $20 \mathrm{keV}$, $7.2 \mathrm{nA}$, and $0.9 \times 10^{5}$ electrons $\mathrm{nm}^{-2} \mathrm{~s}^{-1}$. Table III shows that the 10 min irradiation treatment reduced resistivity from $7200 \pm 100$ to $215 \pm 15 \mu \Omega \mathrm{cm}$. Further postgrowth irradiation (up to a total of $30 \mathrm{~min}$ ) did not significantly change the resistivity, indicating that the effects of electron irradiation saturate at high electron fluence. It should be noted that this resistivity is only 20 times larger than the bulk resistivity of platinum. This value has only been surpassed to date (for this precursor) by Barry et al. ${ }^{6}$ by using exceedingly high beam currents (upward of $3 \mathrm{nA}$ ) and a growth time of $20 \mathrm{~min}$. Table III also shows that the deposit height (measured by atomic force microscopy) decreases with postgrowth irradiation time, suggesting that deposit compaction occurs, which is consistent with the deposit densification observed by TEM.

\section{DISCUSSION}

High-resolution TEM revealed that both the ESEM (Figs. 1-3) and HV (Fig. 6) modes of EBID yield the same trends in microstructure evolution with electron fluence. Further-
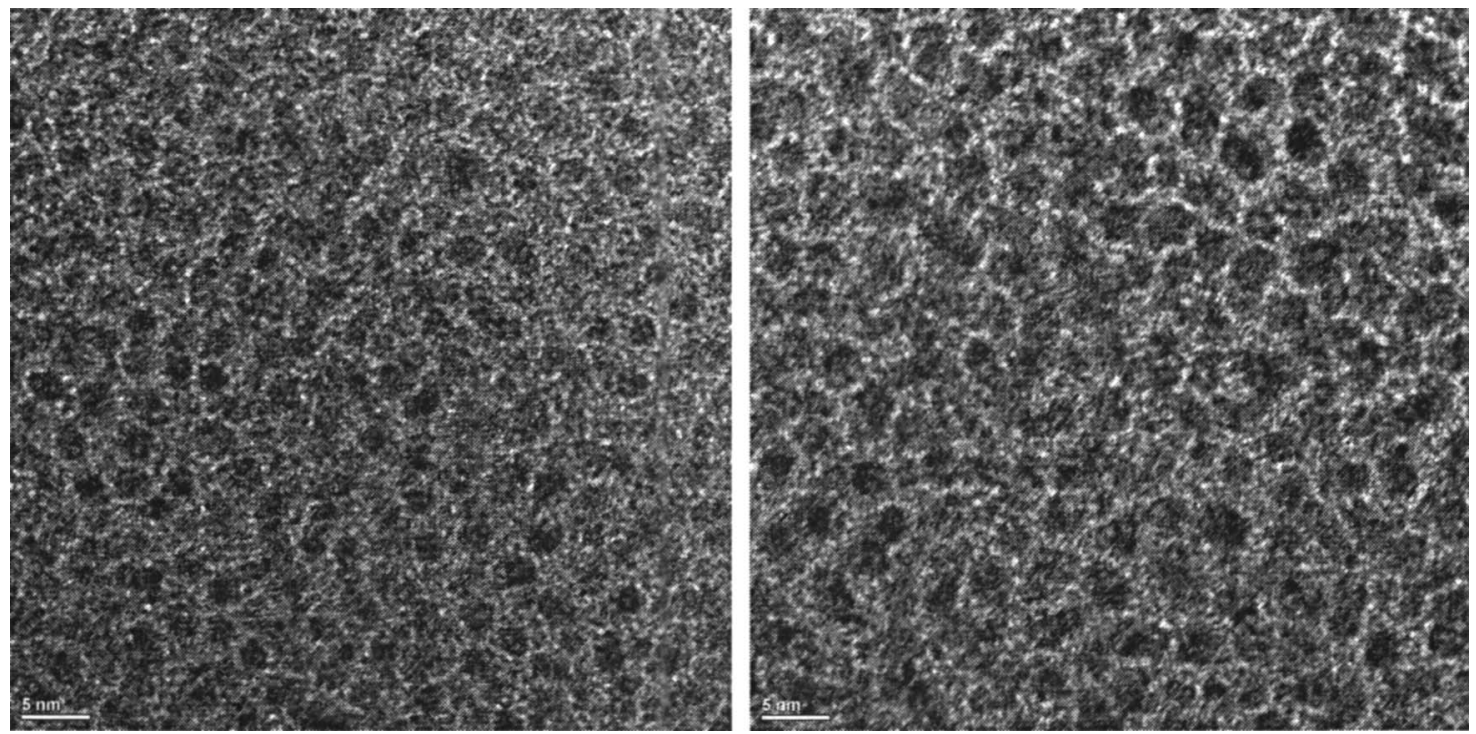

FIG. 5. TEM images of two thin samples analyzed in Fig. 4, illustrating the microstructure of an as-grown deposit (left) and one that was irradiated after deposition, for $20 \mathrm{~min}$ (right). The scale bar is $5 \mathrm{~nm}$. 

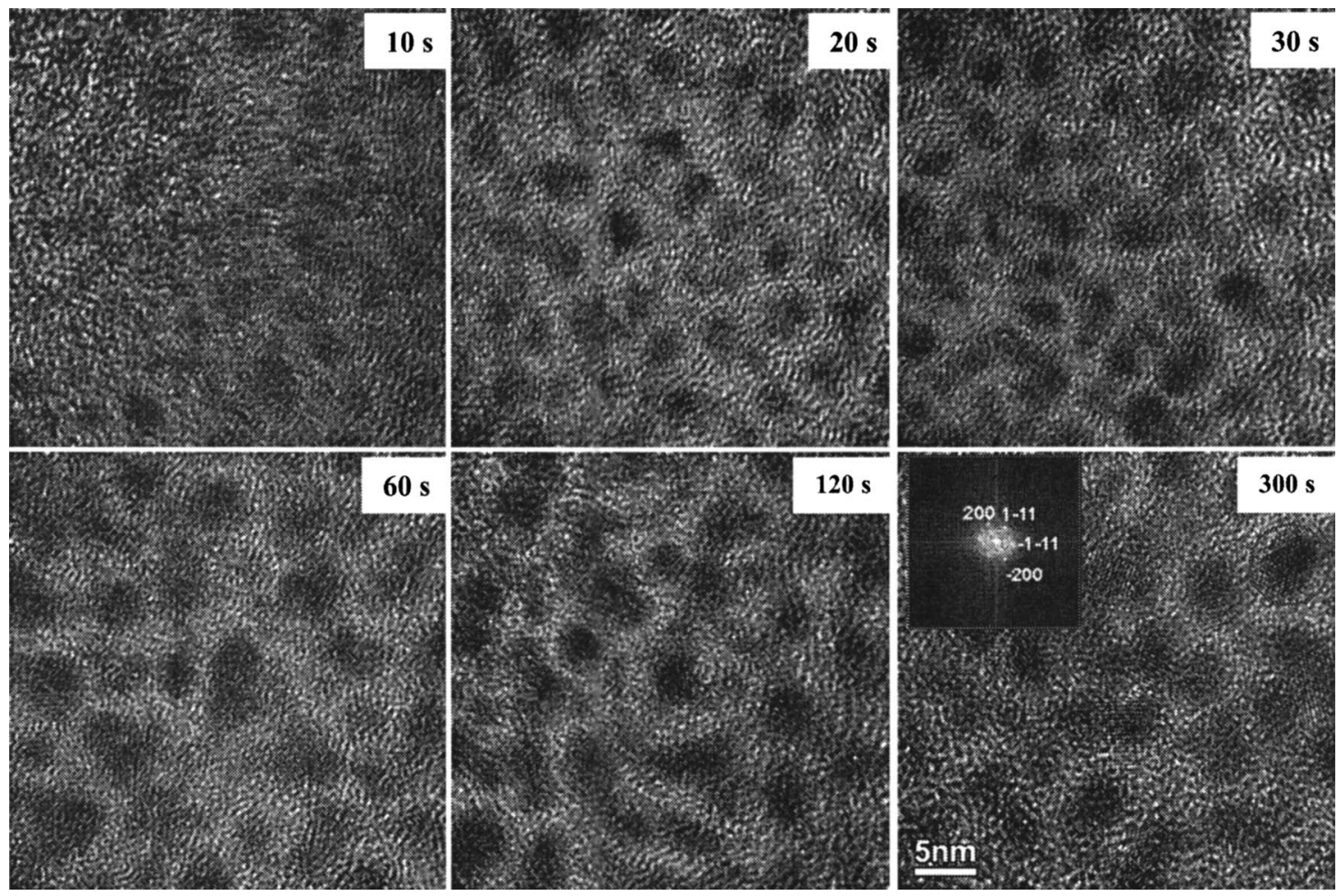

FIG. 6. TEM images acquired from deposits fabricated as a function of growth time. Each image was taken from the center of a deposit. The images show that both the degree of crystallinity and grain size increase with deposition time.

more, the results illustrate that, qualitatively, electron processing occurring during and after growth leads to equivalent changes in microstructure, although postgrowth irradiation is more efficient at creating larger platinum nanocrystallites.

It is currently unclear what physical mechanisms are causing the observed effects. Possible mechanisms include drift of charged species under the influence of electric fields generated by excess charge inside the electron-irradiated solids, from bond breakage caused by energetic electrons; ${ }^{12}$ localized beam-induced heating; or beam-induced desorption of volatile molecules. However, the extent of heating and charging occurring during EBID and during the reported postgrowth irradiation treatments is unknown. Verification of the physical mechanisms behind the observed behavior is beyond the scope of the present investigation.

We note that the effects of TEM analysis on the microstructure of electron beam sensitive materials require consid-

TABLE I. Deposit resistivity measured as a function of electron beam diameter and growth time.

\begin{tabular}{ccc}
\hline \hline $\begin{array}{c}\text { Diameter } \\
(\mu \mathrm{m})\end{array}$ & $\begin{array}{c}\text { Postgrowth irradiation } \\
\text { time } \\
(\mathrm{min})\end{array}$ & $\begin{array}{c}\text { Resistivity } \\
(\mu \Omega \mathrm{cm})\end{array}$ \\
\hline 5 & 3.75 & 11000 \\
& 7.5 & 6018 \\
& 15 & 1740 \\
10 & 15 & 6067 \\
& 60 & 3571 \\
\hline
\end{tabular}

eration. We believe that the trends observed in the present study cannot be accounted for by changes induced by TEM for the following reasons: the deposits are thin, the energy used for the analysis was $200 \mathrm{keV}$, and the electron beam current and analysis time were minimized (each sample region was imaged only once). Thus the time-integrated interaction of the TEM beam with each sample (i.e., the energy density deposited into the solid) is very low compared to that of the 5 or $20 \mathrm{keV}$ SEM beam used for growth and postgrowth processing. Furthermore, the discussed trends show differences between samples fabricated as a function of EBID and postgrowth irradiation parameters, and each TEM dataset was acquired using the same TEM parameters. Hence we expect any changes in material microstructure caused by the TEM beam to be irrelevant to the trends discussed in the present article.

We note that a previous study has shown that profound changes in the morphology of deposits grown from $\mathrm{Pt}\left(\mathrm{PF}_{3}\right)_{4}$ (such as the complete evaporation of phosphorus clusters)

TABLE II. Deposit resistivity measured as a function of electron beam diameter (the growth time was fixed at $15 \mathrm{~min} /$ deposit).

\begin{tabular}{cc}
\hline \hline $\begin{array}{c}\text { Diameter } \\
(\mu \mathrm{m})\end{array}$ & $\begin{array}{c}\text { Resistivity } \\
(\mu \Omega \mathrm{cm})\end{array}$ \\
\hline 5 & 1740 \\
10 & 6067 \\
\hline
\end{tabular}


TABLE III. Deposit resistivity and height measured as a function of postgrowth electron irradiation time.

\begin{tabular}{ccc}
\hline \hline $\begin{array}{c}\text { Postgrowth irradiation } \\
\text { time } \\
(\mathrm{min})\end{array}$ & $\begin{array}{c}\text { Resistivity } \\
(\mu \Omega \mathrm{cm})\end{array}$ & $\begin{array}{c}\text { Deposit height } \\
(\mathrm{nm})\end{array}$ \\
\hline 0 & $7200 \pm 100$ & 338 \\
10 & $215 \pm 15$ & 179 \\
30 & $215 \pm 15$ & 159 \\
\hline \hline
\end{tabular}

can occur during TEM analysis. ${ }^{7}$ The extreme TEM conditions needed to cause such effects were, however, intentionally avoided in the present study.

It is interesting to note that Kerr et al. ${ }^{13}$ recently observed a decrease in the resistivity of deposits made from $\mathrm{W}(\mathrm{CO})_{6}$ with increasing deposit height or equivalently increasing deposition time. We suggest that those results are similar to the phenomena discussed in the present article in that longer deposition times led to increased electron beam processing of an EBID-grown material.

\section{CONCLUSIONS}

In conclusion, we have demonstrated that the material deposited by EBID using the precursor $\mathrm{Pt}\left(\mathrm{PF}_{3}\right)_{4}$ is beam sensitive, evolves with electron fluence delivered to the solid, and that this behavior can be used to tailor the properties of the deposited material. We have shown how the grain size varies with deposition and postgrowth electron irradiation time. We have further shown that resistivity of the deposited material can be improved by postgrowth electron irradiation, with the best value obtained of $215 \pm 15 \mu \Omega \mathrm{cm}$. We demonstrated that electron beam-induced modification of EBID deposits grown from $\operatorname{Pt}\left(\mathrm{PF}_{3}\right)_{4}$ occurs under electron fluences similar to those used in typical EBID processes. Finally, we suggest that SEM operators can control the observed changes in microstructure and deposit functionality by optimal selection of growth conditions and by postgrowth electron irradiation. Both approaches can be performed in situ without breaking vacuum.

\section{ACKNOWLEDGMENT}

The authors thank Christoph Mitterbauer (FEI Electron Optics) for his help with some of the TEM analysis.

${ }^{1}$ S. J. Randolph, J. D. Fowlkes, and P. D. Rack, Crit. Rev. Solid State Mater. Sci. 31, 55 (2006).

${ }^{2}$ I. Utke, P. Hoffmann, and J. Melngailis, J. Vac. Sci. Technol. B 26, 1197 (2008).

${ }^{3}$ T. Brintlinger, M. S. Fuhrer, J. Melngailis, I. Utke, T. Bret, A. Perentes, P. Hoffmann, M. Abourida, and P. Doppelt, J. Vac. Sci. Technol. B 23, 3174 (2005).

${ }^{4}$ H. W. P. Koops, C. Schoessler, A. Kaya, and M. Weber, J. Vac. Sci. Technol. B 14, 4105 (1996)

${ }^{5}$ Y. M. Lau, P. C. Chee, J. T. L. Thong, and V. Ng, J. Vac. Sci. Technol. A 20, 1295 (2002).

${ }^{6}$ J. D. Barry, M. Ervin, J. Molstad, A. Wickenden, T. Brintlinger, P. Hoffman, and J. Melngailis, J. Vac. Sci. Technol. B 24, 3165 (2006).

${ }^{7}$ A. Botman, M. Hesselberth, and J. J. L. Mulders, J. Vac. Sci. Technol. B 26, 2464 (2008).

${ }^{8}$ J. Li, M. Toth, A. Botman, K. A. Dunn, C. J. Lobo, R. L. Moore, and B. L. Thiel (unpublished).

${ }^{9}$ M. Takeguchi, M. Shimojo, and K. Furuya, Appl. Phys. A: Mater. Sci. Process. 93, 439 (2008).

${ }^{10}$ J. Li, M. Toth, V. Tileli, K. A. Dunn, C. J. Lobo, and B. L. Thiel, Appl. Phys. Lett. 93, 023130 (2008).

${ }^{11}$ V. Friedli and I. Utke, J. Phys. D 42, 125305 (2009).

${ }^{12}$ J. Cazaux, J. Electron Spectrosc. Relat. Phenom. 105, 155 (1999).

${ }^{13}$ G. L. Kerr, D. C. Cox, V. Stolojan, and S. R. P. Silva, J. Phys.: Conf. Ser. 126, 012073 (2008). 